\title{
EXPERIMENTAL INVESTIGATION OF PERFORMANCE AND COMBUSTION CHARACTERISTICS ON A SINGLE CYLINDER LHR ENGINE USING DIESEL AND MULTI-BLEND BIODIESEL
}

\author{
Balkrishna K Khot ${ }^{1}$, Prakash S Patil ${ }^{2}$, Omprakash Hebbal ${ }^{3}$ \\ ${ }^{1} P G$ Student, Thermal Power Engineering PDACE Gulbarga, Karnataka, India \\ ${ }^{2}$ Associate professor, ${ }^{3}$ Professor, Dept of Mechanical Engineering PDACE Gulbarga, Karnataka, India
}

\begin{abstract}
In this study, for the first time, a nanoceramic Al2O3 was used as a coating material in the low heat rejection engine concept. Experiments were conducted on single cylinder, four stroke, water cooled, and direct injection diesel engine. First, the engine was tested at different load conditions without coating. Then, combustion chamber surfaces cylinder head, cylinder liner, valves, and piston crown face were coated with nanoceramic material of Al2O3 using plasma spray method. Comparative evaluation on performance and combustion characteristics using diesel, multi-blend biodiesel and its blends was studied in the ceramic coated and uncoated engines under the same running conditions. An increase in engine power, brake thermal efficiency and a decrease in specific fuel consumption were observed in the ceramic coated engine compared to that of normal engine.
\end{abstract}

Keywords: Multi-blend biodiesel, low heat rejection engine

\section{INTRODUCTION}

The rapid increase in fuel expenses, the decreasing supply of high-grade fuels on the market, stimulated research on more efficient engines. Thermal barrier coatings provide the potential for higher thermal efficiencies of the engine, improved combustion, and reduced emissions. Lower heat rejection from the combustion chamber through thermally insulated components causes an increase in available energy that would increase the in-cylinder work and the amount of energy transported by the exhaust gases, which could be also utilized.

Energy demand around the world is increasing rapidly as a result of ongoing trends in modernization and industrialization. Most of the developing countries import fossil fuels to satisfy their energy demands. Consequently, these countries have to spend their export income earned under severe conditions to buy petroleum products. The environment is also affected negatively due to the combustion of fossil fuels. In the current situation, the main considerations are the decrease in availability of fossil fuels and environmental pollution. Therefore, it is necessary to develop low emission alternative fuels for diesel engines. As a result, vegetable oils are an important alternative fuel source for diesel engines. Higher flash points and better lubricating ability are the positive characteristics of biodiesel. However, high viscosity and low evaporation of vegetable oil-based fuels make their use as a fuel more difficult. A couple of methods are available for modifying vegetable oils to make them suitable for use in engines. Transesterification has shown good potential for reducing engine problems associated with vegetable oils. This process decreases viscosity and improves the cetane number and heating value. Biodiesel is a fuel that can be used directly in diesel engines without any modification or with a small modification. The use of biodiesel fuel improves exhaust emission values due to higher oxygen content. Although fuel characteristics of biodiesels are made similar to those of the diesel fuel with the help of transesterification method, their viscosity value is still higher than that of the diesel fuel. To eliminate this negative effect, biodiesel is introduced to the combustion chamber after heating and thus can be used in diesel engines more efficiently. However, the insulation of the combustion chamber elements causes an after-combustion temperature increase in ceramic coated diesel engines; biodiesel can be used more efficiently in these engines. Thus, biodiesel can be used without preheating in coated engines.

Ceramic coating is generally applied on the cylinder head, the piston, and valves by plasma spray method. Coating these parts with ceramic also absorbs the negative effects of wear, friction, heating, corrosion, and oxidation and protects the substrate. The temperature in the combustion chamber is higher in the ceramic coated engines than that of uncoated engines; it is possible to use lower-quality fuels within a wider distillation range. 


\section{MATERIALS AND METHODS}

\subsection{The Properties of Diesel Fuel and}

\section{Multi-Blend Biodiesel}

The different properties of diesel fuel and JOME and POME are determined and given in below table. After transisterification process the fuel properties like kinematic viscosity, CV, density, flash and fire point get improved in case of biodiesel. The calorific value of methyl ester is lower than that of diesel because of oxygen content. The flash and fire point temperature of biodiesel is higher than the pure diesel fuel this is beneficial by safety considerations which can be stored and transported without any risk.

Table 2.1 fuel properties

\begin{tabular}{|l|l|l|}
\hline Properties & $\begin{array}{l}\text { Diesel } \\
\text { fuel }\end{array}$ & $\begin{array}{l}\text { Multi-blend } \\
\text { biodiesel }\end{array}$ \\
\hline $\begin{array}{l}\text { Kinematic viscosity at } \\
\text { 400 C (cst) }\end{array}$ & 3.0 & 6.5 \\
\hline Calorific value(KJ/Kg) & 42680 & 40498 \\
\hline Density $(\mathrm{Kg} / \mathrm{m} 3)$ & 0.830 & 0.880 \\
\hline Flash point $(0 \mathrm{C})$ & 50 & 153 \\
\hline Fire point(0C) & 57 & 163 \\
\hline
\end{tabular}

\section{EXPERIMENTATION}

\subsection{Engine Components}

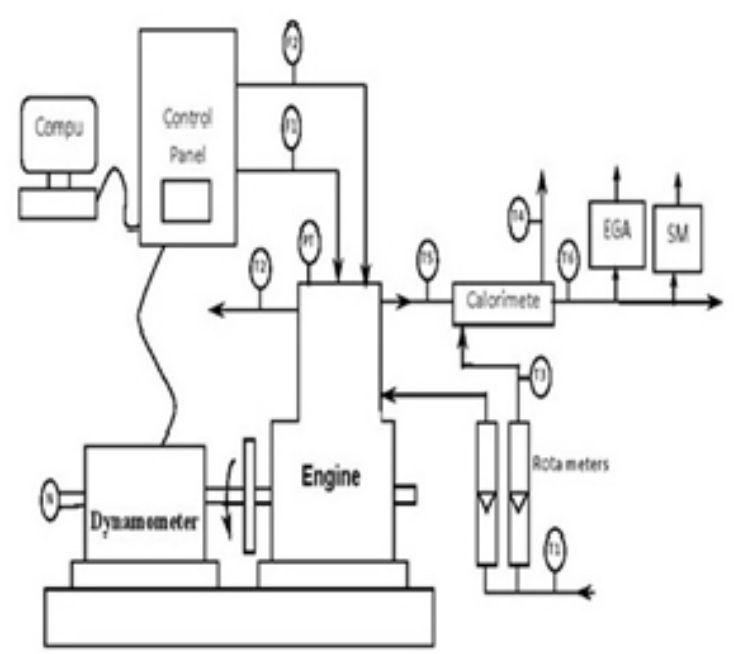

Figure.3.1 shows the line diagram or various components of experimental set up.

The important components of the system are:

1. The engine

2. Dynamometer
Table 3.1 Gives the notations

\begin{tabular}{|l|l|}
\hline PT & Pressure transducer \\
\hline N & Rotary encoder \\
\hline Wt & Weight \\
\hline F1 & Fuel flow \\
\hline F2 & Air flow \\
\hline F3 & Jacket water flow \\
\hline F4 & Calorimeter water flow \\
\hline T1 & Jacket water inlet temperature \\
\hline T2 & Jacket water outlet temperature \\
\hline T3 & Calorimeter water inlet temperature $=$ T1 \\
\hline T4 & Calorimeter water outlet temperature \\
\hline T5 & Exhaust gas to calorimeter temperature \\
\hline T6 & \\
\hline
\end{tabular}

Table 3.2 Engine specifications

\begin{tabular}{|ll|}
\hline Manufacturer & Kirloskar oil engines Ltd, India \\
Model & TV-SR, naturally aspirated \\
Engine & Single cylinder, DI \\
Bore/stroke & $87.5 \mathrm{~mm} / 110 \mathrm{~mm}$ \\
C.R. & $16.5: 1$ \\
speed & $1500 \mathrm{r} / \mathrm{min}$, constant \\
Rated power & $5.2 \mathrm{kw}$ \\
Working cycle & four stroke \\
Injection pressure & $200 \mathrm{bar} / 23$ def TDC \\
Type of sensor & Piezo electric \\
Response time & 4 micro seconds \\
Crank angle sensor & 1-degree crank angle \\
Resolution of 1 deg & 360 deg with a resolution of 1deg \\
\hline
\end{tabular}


4 COMPARATIVE

ANALYSIS OF

PERFORMANCE

AND

COMBUSTION

CHARACTERISTICS

OF

MULTI-BLEND

BIODIESEL BLENDS AND DIESEL ON NORMAL

ENGINE AND LOW HEAT REJECTION ENGINE:

\subsection{Variation of Brake Thermal Efficiency with}

\section{Brake Power}

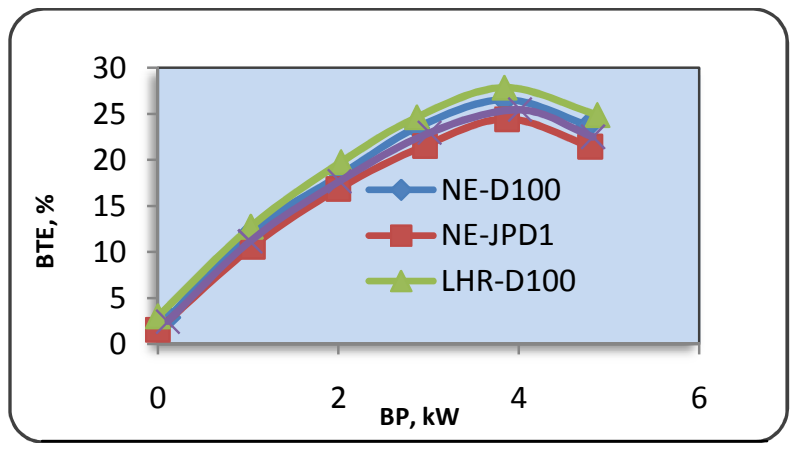

Fig 4.1 Variation of indicated mean effective pressure with brake power

Fig 4.1 shows the break thermal efficiency for multi-blend biodiesel and its blends with respect to brake power for normal engine and low heat rejection engine. The maximum efficiency obtained in the case of LHR engine fueled with biodiesel at full load was lower than LHR engine fueled with diesel and higher than normal engine fueled with diesel and biodiesel. The efficiency of normal engine JPD1 and LHRJPD1 at full load are almost same this is due to complete combustion of fuel in thermal barrier coated engine.

\subsection{Variation of Mechanical Efficiency with Brake}

\section{Power}

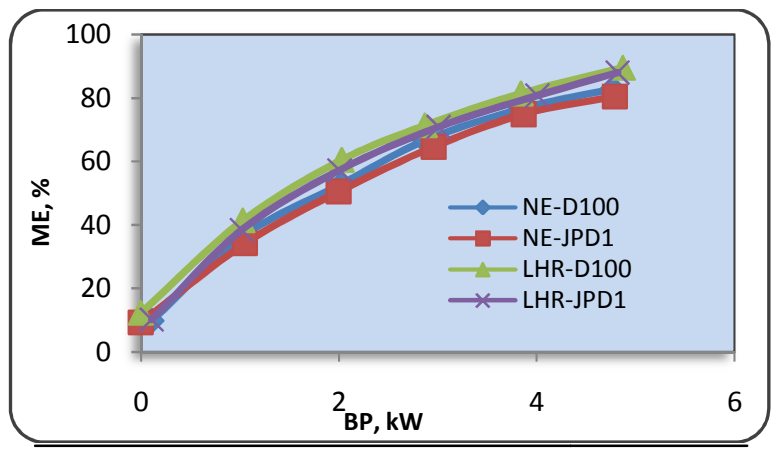

Fig 4.2 Variation of mechanical efficiency with brake power

The variation of mechanical efficiency with brake power, for diesel and multi-blend biodiesel blends are as shown in figure.4.2 for normal engine and LHR engine. The mechanical efficiency of diesel is slightly higher than the multi-blend biodiesel for both normal engine and LHR engine. From the graph it is evident that with increase in the concentration of multi-blend biodiesel in diesel decreases the mechanical efficiency. The maximum mechanical efficiency at full load for LHR engine with D100 and JPD1 is 89.45 and 87.96 which is higher than the normal engine with D100 and JPD1 is 82.86 and 80.47 Here we can see the effect of thermal barrier coating which increases the mechanical efficiency.

\subsection{Variation of Specific Fuel Consumption with} Brake Power

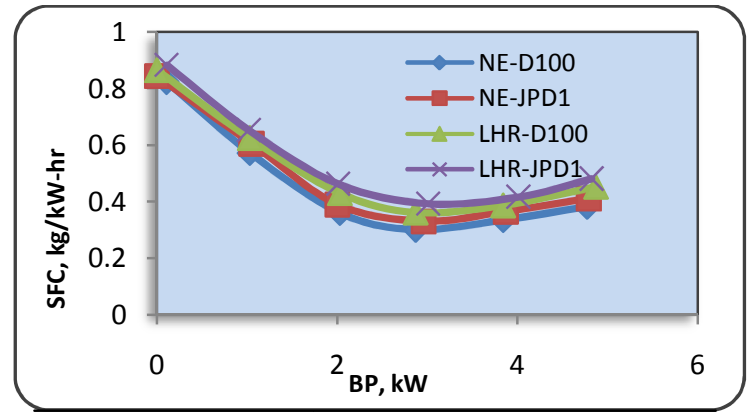

Fig 4.3 Variation of specific fuel consumption with brake power

Fig 4.3 shows the specific fuel consumption for multi-blend biodiesel and its blends with respect to brake power for both normal engine and LHR engine. At maximum load the specific fuel consumption of LHR engine fueled with biodiesel is higher than LHR engine fueled with diesel and lower than normal engine fueled with diesel and biodiesel. This higher fuel consumption was due to the combined effect of lower calorific value and high density of biodiesel. The test engine consumed additional biodiesel fuel in order to retain the same power output.

\subsection{Variation of Indicated Mean Effective Pressure} with Brake Power

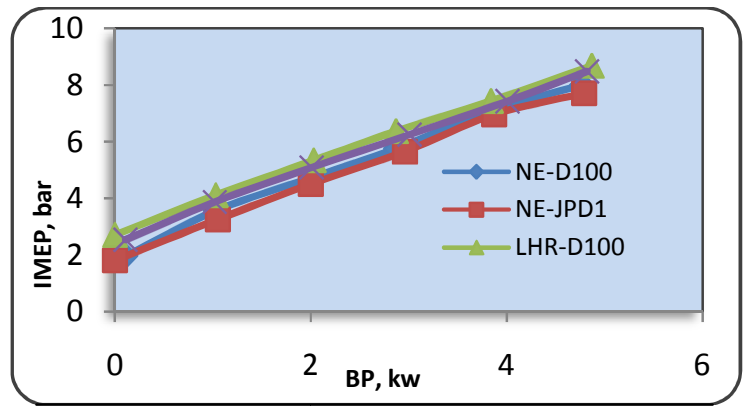

Fig 4.4 Variation of indicated mean effective pressure with brake power 
The variation of the mean indicated pressure with respect to brake power for diesel and multi-blend biodiesel blends are shown in figure 4.4 Indicated mean effective pressure is low for multi-blend biodiesel compared to diesel this is due to volatility and lower calorific value of multi-blend biodiesel.

\subsection{Variation of Air-Fuel Ratio with Brake Power}

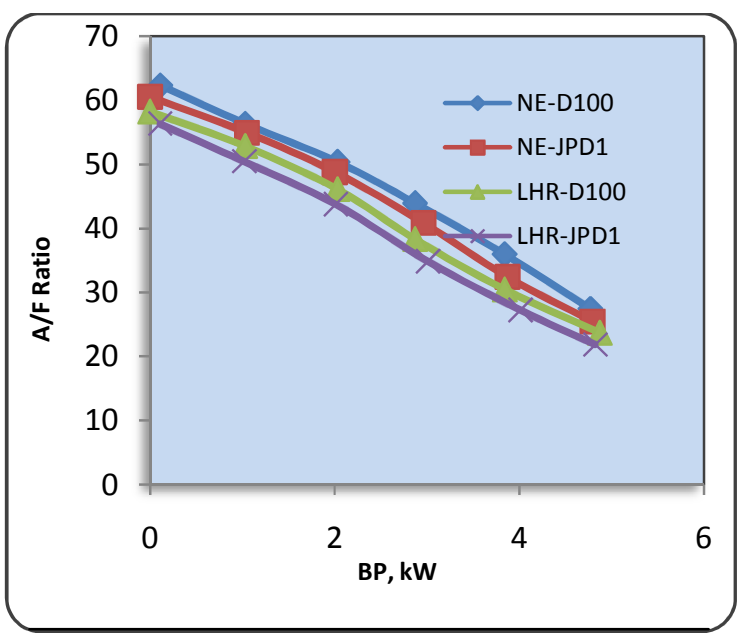

Figure 4.5 Variation of air-fuel ratio with brake power

The variation of air fuel ratio for diesel and multi-blend biodiesel is shown in fig 4.5 for both normal engine and LHR engine. Because of increased temperature and complete combustion the fuel consumption is higher in case of LHR engine. Air fuel ratio decreases with increase in load because air fuel mixing process is affected by the difficulty in atomization of biodiesel due to its higher viscosity.

\subsection{Variation of Exhaust Gas Temperature with}

\section{Brake Power}

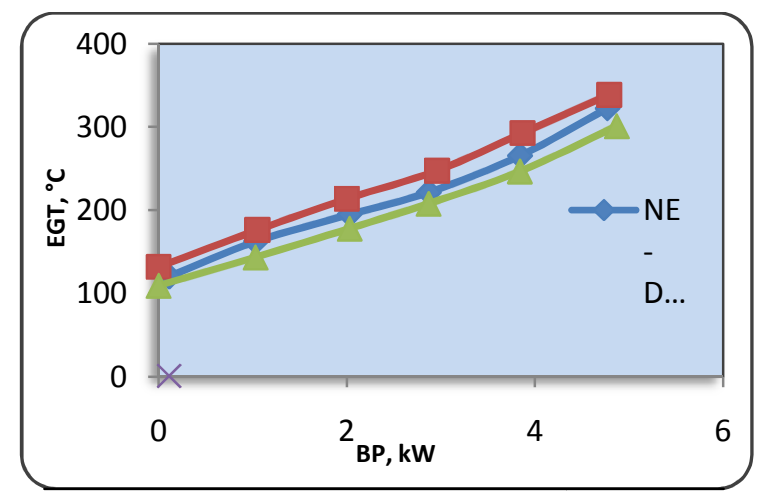

Fig 4.6 Variation of exhaust gas temperature with brake power

The variation of exhaust gas temperature for diesel and multiblend is shown in fig 4.6 for both normal engine and LHR engine. When bio fuel concentration increases in the diesel the exhaust temperature increases due to thermal barrier coating. Also as the load increases the exhaust gas temperature increases.

\subsection{Variation of Volumetric Efficiency with Brake}

Power

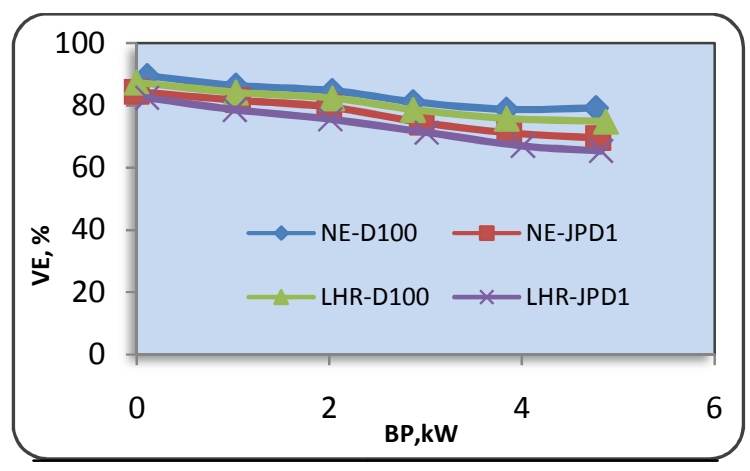

Fig 4.7 Variation of volumetric efficiency with brake power

The variation of the volumetric efficiency with respect to brake power for diesel and multi-blends is shown in figure 4.7 From the above graph we concluded that there is no much difference in volumetric efficiency with each load. But volumetric efficiency for NE-D100 is slightly higher than the LHR-D100, because of increase of temperature due to thermal barrier coating.

\subsection{Variation of Crank Angle V/S Cylinder Pressure}

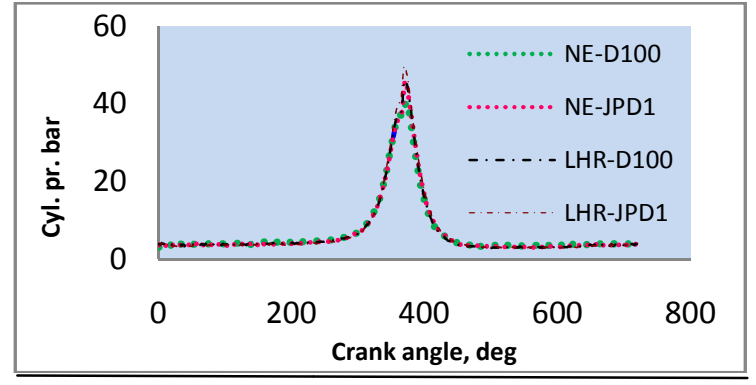

Fig 4.8 Variation of crank angle v/s cylinder pressures

In a CI engine the cylinder pressure is depends on the fuelburning rate during the premixed burning phase, which in turn leads better combustion and heat release. Figure 4.8 shows the typical variation of cylinder pressure with respect to crank angle. The cylinder pressure in the case of biodiesel fueled LHR engine is lesser than the diesel fueled LHR engine and higher than conventional engine fueled with diesel and biodiesel. This reduction in the cylinder pressure may be due to lower calorific value and slower combustion rates associated with biodiesel fueled LHR engine. 


\section{CONCLUSIONS}

The following conclusions were drawn from the experimental analysis carried out on normal engine and LHR engine for different loads:

- It is observed that JPD1 multi-blend biodiesel has mechanical efficiency, specific fuel consumption and indicated thermal efficiency almost nearer to the diesel fuel

- There is slight increase in brake thermal efficiency which is a positive sign with this blend. In case of peak pressure it is seen that there is almost same pressure as that of diesel fuel. So it can be concluded that the multi-blend biodiesel can be used without any modification in the existing engine which will result in saving of diesel fuel for certain extent without any compromise with standard performance and combustion characteristics.

- After little modification in engine, it is observed that there is increase in the performance of parameters such as brake thermal efficiency, mechanical efficiency and brake mean effective pressure and there is decrease in specific fuel consumption, volumetric efficiency compared to the normal engine.

- The use of multi-blend biodiesel in insulated engine gave the highest brake thermal efficiency at all loads due to the better utilization of the higher amount of energy conserved inside the combustion chamber.

- By the application of the thermal barrier coating, the improvement in the specific fuel consumption caused an increase of the brake thermal efficiency for multi-blend biodiesel in LHR engine.

- The Volumetric efficiency drops due to the higher cylinder temperature in LHR Engine. It can be compensated by forced induction methods like supercharging and turbo charging.

- By studying performance and combustion characteristics on normal engine and low heat rejection engine it can be concluded that with JPD1 blend we can achieve same characteristics as that of diesel fuel so JPD1 is the best blend.

\section{REFERENCES}

[1] Mohammed Harun Chakrabarti, Mehmood Ali "Performance of Compression Ignition Engine with Indigenous Castor oil Biodiesel in Pakistan" Ned University Journal of Research, Vol VI, No.1, 2009

[2] Sergio C. Capareda "Performance and Exhaust Emission of Cottonseed oil Biodiesel" Beltwide Cotton Conferences 8-11-2008

[3] L. Ranganathan,"Experimental Investigation of a Diesel Engine Fuelled with optimum Biodiesel Produced from Cotton Seed oil" European Journal of Scientific Research Vol 62, No. 1, 2011
[4] M.Bassyouni, F.H.Akhtar "Biodiesel Production and Investigation on the Performance of Diesel Engine using Jatropha oil" ATE, Vol 2, Issue 3, July 2012

[5] N. Janardhan, M.V.S. Murali Krishna. "Performance Evaluation of Low Heat Rejection Diesel Engine with Jatropha" IJEI, Vol 1, Issue 2, September 2012

[6] M. Prabhahar, R. Murali Manohar. "Performance and Emission Studies of a Diesel Engine with Pongamia Methyl Ester at Different Load Conditions" IJERA, Vol 2, Issue 3, May-June 2012

[7] Anpu M V, Ajaya Varma K, Dr. Baiju B. "Experimental Investigation of a Diesel Engine Performance Parameters using Methyl Esters of Sunflower oil" NATCON 2011 